\title{
A Systematic Review on the Feasibility of Salivary Biomarkers for Alzheimer's Disease
}

Mohamed Bouftas ( $\nabla$ mbouf7@gmail.com )

Research article

Keywords: Alzheimer, biomarker, saliva

Posted Date: November 25th, 2019

DOI: https://doi.org/10.21203/rs.2.17674/v2

License: (9) (i) This work is licensed under a Creative Commons Attribution 4.0 International License. Read Full License

Version of Record: A version of this preprint was published at The Journal of Prevention of Alzheimer's Disease on January 1st, 2020. See the published version at https://doi.org/10.14283/jpad.2020.57. 


\section{Abstract}

Background: Early AD diagnosis is critical for ameliorating prognosis and treatment. The analysis of CSF biomarkers yields accurate results, but it necessitates a lumbar puncture procedure. Screening for peripheral biomarkers in saliva is advantageous since this medium is noninvasive and inexpensive to obtain. The objective of this systematic review is to analyze saliva biomarker studies which aim to diagnose AD. Methods: Titles, abstracts, and reference lists for publications from February 2004 to March 2019 were screened for by searching Google Scholar and PubMed. The inclusion criteria involved published studies that consisted of both $A D$ and control groups. Results: 77 studies were screened, and 13 publications fulfilled the inclusion criteria. These selected publications were scrutinized and included in this review. Numerous biomarkers were analyzed, including A 42 , tau, and various salivary metabolites. Conclusion: $A \beta 42$, tau, lactoferrin, and various metabolites might serve as a reliable biomarkers for AD diagnosis. However, these studies must be replicated with a large sample size. It is also important to standardize the analytical methods of measuring salivary biomarkers to establish coherence for the selection of valid AD biomarkers. Saliva composition can be affected by production rate, circadian rhythms, and oral health, so their cumulative effect on the accuracy of saliva testing requires further investigation. Keywords: Alzheimer, biomarker, saliva

\section{Background}

Alzheimer's Disease (AD) is the most common cause of dementia. Approximately $60 \%$ to $70 \%$ of dementia cases pertain to AD [7]. AD affects 46 million individuals, and 131.5 million people are projected to have $A D$ by 2050 [1]. The prevalence of $A D$ is most common among the senior demographic (65+). Its direct cause is unclear, but a multitude of neurodegenerative processes have been associated with the disease. The formation of intracellular amyloid plaques and neurofibrillary tau tangles constitute some of the neuropathological hallmarks of AD. These compounds are expressed several decades before AD can be clinically diagnosed.

There are several ongoing clinical trials that aim to halt the progression of $A D$ in presymptomatic stages. Aducanumab and Solanezumab are monoclonal antibodies that have been investigated for their potency against soluble $A \beta$ oligomers. After undergoing phase III trials, it was concluded that neither drug significantly affected cognitive decline $[4,11]$. This suggests that "plaque-busting" drugs may yield no significant effect if administered during the symptomatic phase of AD. Therefore, there is a pressing need to develop a simple and non-invasive test which can pinpoint the presence of $A D$ in its presymptomatic phase so that treatment can mitigate its neurodegenerative effect.

Currently, an array of clinical approaches are implemented to determine the presence of AD. Utilizing a biomarker-driven test may also aid in establishing an early diagnosis. Biomarkers in CSF are used to 
detect AD. Analyzing levels of A 342 , tau, and phosphorylated tau in CSF is an accurate approach [5], but this method is both costly and invasive. Biomarkers in saliva are being explored as an alternative diagnostic approach.

Significantly altering the autonomic nervous system (ANS) function may have an effect on salivary production and composition [9]. The ANS is responsible for maintaining saliva secretion by innervating the glossopharyngeal cranial nerve and the facial cranial nerve. During presymptomatic $A D$, damage is induced to the nerve endings of the cholinergic system, which compromises ANS function. Saliva contains a plethora of biomarkers, as about $40 \%$ of diagnostic blood proteins are also found in saliva [13]. It features many advantages for diagnostic purposes compared to other bodily fluids. Saliva is both cheap and easy to obtain, as it can be collected in a non-invasive manner. These advantages facilitate the sampling process of this medium, which is useful for rapid disease screening. The objective of this review is to provide an overview of the literature pertaining to the utility of saliva as a medium for analyzing biomarkers that are specifically associated with $A D$. Developing accurate salivary diagnostics can facilitate early intervention of $A D$, which in turn may improve $A D$ treatment.

\section{Methods}

A standard protocol was implemented for selection of publications in this review. PubMed and Google Scholar were used to conduct a literature search for publications from February 2004 to March 2019. Searches were conducted with the following keywords: Alzheimer, biomarker, dementia, saliva. Titles, abstracts, and reference lists were used to select pertinent publications. Studies included in this systematic review are original publications that analyze potential salivary AD biomarker candidates. Each study consisted of saliva samples from both $A D$ subjects and control subjects. Subject metrics such as age, gender, and sample size for both $A D$ and control groups were considered, along with biomarker type, technique of biomarker quantification, and statistical analysis.

\section{Results}

Of the 77 screened studies, 13 were selected, scrutinized, and included in this review. Several studies determined the potential utility of $A \beta 42$ and tau as salivary biomarkers, but other compounds including acetylcholinesterase, lactoferrin, trehalose, and metabolites were investigated as well.

Acetylcholinesterase 
Salivary acetylcholinesterase (AchE) levels were analyzed in two studies. Ellman's colorimetric method was implemented for both of the studies. Bakhtiari et al. tested saliva samples from 15 AD subjects and 15 control subjects. Higher levels of AchE was reported, but statistical significance was not established. Sayer et al. tested saliva samples from 47 volunteers (22 AD cases, 14 AD nonresponder cases, and 11 control cases). They found an overall negative correlation between age and AchE levels, as the r-value was -0.768 (with $p<0.001$ ). It was also reported that $A D$ subjects had $73 \%$ lower levels of $A c h E$ in comparison to control subjects (with $p<0.005$ ) [22].

$\underline{A} \underline{\beta 42}$

Salivary A 342 levels were analyzed in four studies, and all of them utilized an enzyme-linked immunosorbent-type assay (ELISA) with the exception of one. Bermejo-Pareja et al. tested 126 saliva samples from both $A D$ and control cases, in addition to 51 saliva samples from Parkinson's patients. They concluded that salivary $A \beta 42$ levels were significantly greater in patients suffering from mild to moderate AD, but not for patients with severe AD. Their results did not conclude a significant difference between Parkinson's patients and controls. Lee et al. analyzed the expression of A $\beta 42$ in both saliva and other tissues. 37 volunteers participated in the study, including 27 non-AD and $7 A D$ cases. They reported a mean of $22.060 .41 \mathrm{pg} / \mathrm{mL}$ of salivary $A \beta 42$ for the non-AD cases and a mean of $59.076 .33 \mathrm{pg} / \mathrm{mL}$ for the $A D$ cases. Kim et al. utilized an immunoassay containing nanobeads to detect salivary $A \beta 42$ levels for 45 individuals ( $28 \mathrm{AD}$ cases and 17 normal controls). Their results concluded higher levels of salivary $A \beta 42$ for the $A D$ cases vs. control cases, but their study did not have a p-value. Sabbagh et al. analyzed salivary $A \beta 42$ levels from 15 AD patients and 7 normal controls. They reported a mean of $21.10 .3 \mathrm{pg} / \mathrm{mL}$ for the normal controls and a mean of $51.71 .6 \mathrm{pg} / \mathrm{mL}$ for $A D$ cases, with $p<0.001$.

$\underline{\mathrm{Tau}}$

Salivary tau levels were analyzed in three studies. Ashton et al. tested 213 saliva samples from both AD and control cases, in addition to 68 saliva samples from individuals with aMCl. This study used the single-molecule array (SIMOA) technique to analyze total tau levels. Increased t-tau levels in AD patients were observed, but statistical significance was not established. Shi et al. utilized an ELISA to analyze ptau and t-tau levels. 59 volunteers participated in this study, which included 21 AD cases and 38 control cases. Increased $p$-tau/t-tau ratio levels were reported for AD patients, with $p<0.05$. Pekeles et al. obtained unstimulated saliva in order to analyze the $\mathrm{p}$-tau/t-tau ratio at different phosphorylation sites (S396,S400,S404,T403,T404). This study implemented the Western Blot analysis method to quantify their findings. 337 volunteers participated throughout the two clinical studies conducted by Pekeles et al., 
including $87 \mathrm{AD}$ subjects and 167 control subjects. Their first study included $55 \mathrm{aMCl}$ subjects as well, and their second study included 16 FTD subjects and an additional 12 neurological patients that did not suffer from dementia. Their findings indicated a significantly higher $\mathrm{p}$-tau/t-tau ratio at the $\mathrm{S} 396$ site for $\mathrm{AD}$ patients in comparison to the elderly control individuals. However, they reported no correlation between elevated salivary tau levels and both CSF tau and hippocampal volume. There was also significant variation for salivary tau levels in $A D$ subjects, which may pose a limitation towards implementation of tau as a legitimate AD biomarker.

\section{Trehalose and Lactoferrin}

Both trehalose and lactoferrin levels in saliva were analyzed in two studies. Lau et al. utilized an extended gate ion-sensitive field-effect transistor (EG-ISFET) biosensor to analyze salivary trehalose. 60 saliva samples were tested, including 20 AD subjects, 20 PD subjects, and 20 control subjects. Higher salivary trehalose levels were found in the AD subjects, but statistical significance was not established. Carro et al. used an ELISA to detect salivary lactoferrin levels. The objective was to determine if decreased lactoferrin levels could serve as an indicator of AD. 365 individuals participated throughout the two clinical studies conducted by Carro et al., including 116 AD subjects, 59 aMCl subjects, and 131 control subjects. Their first study also included $59 \mathrm{aMCl}$ subjects. Mass spectrometry was implemented to confirm that this protein could be detected in saliva before further experimentation. This study also analyzed salivary lactoferrin levels for $\mathrm{aMCl}$ and PD subjects. Carro et al. concluded (with $\mathrm{p}<0.001$ ) significantly lower levels for both $\mathrm{AD}$ and $\mathrm{aMCl}$ subjects in comparison with the control subjects, but $\mathrm{PD}$ subjects had significantly higher levels in comparison with control subjects. $7.43 \mu \mathrm{g} / \mathrm{mL}$ was the established cutoff value between $\mathrm{AD} / \mathrm{MCl}$ subjects and controls in this study.

\section{Metabolites}

Salivary metabolites were analyzed in two studies, which totaled $285 \mathrm{AD}$ subjects, $35 \mathrm{aMCl}$ subjects, and 263 control subjects. Huan et al. used liquid chromatography mass spectrometry (LC-MS) to assess the following metabolites: alanylphenylalanine, aminobytyric acid $+\mathrm{H} 2$, amino-dihydroxybenzene, cholinecytidine, glucosyl-galactosyl-hydroxylysine * $(\mathrm{H} 2 \mathrm{O})$, histidylphenylalanine, methylguanosine, phenylalanylphenylalanine, phenylalanylproline, and urocanic acid. Their work featured two clinical studies to further confirm their findings. Between AD and control subjects, there was a significant difference for the following metabolites (with $p<0.01$ ): choline-cytidine, histidylphenylalanine, methylguanosine, phenylalanylphenylalanine, phenylalanylproline, and urocanic acid. Between $A D$ and aMCl subjects, there was a significant difference for the following metabolites (with $p<0.01$ ): 
alanylphenylalanine, aminobytyric acid $+\mathrm{H} 2$, amino-dihydroxybenzene, glucosyl-galactosyl-hydroxylysine * (H2O), and phenylalanylproline. Q. Liang et al. implemented ultraperformance liquid chromatography mass spectrometry (UPLC-MS) to assess the following metabolites: inosine, ornithine, phenyllactic acid, and spinganine-1-phosphate. They concluded significantly elevated levels of spinganine-1-phosphate and ornithine for $A D$ subjects in comparison to control subjects and significantly lower levels of inosine for $A D$ subjects in comparison to control subjects (with $p<0.01$ ).

\section{Discussion}

This systematic review aims at providing a proper assessment on the literature addressing salivary AD biomarker candidates. The studies observing salivary AchE suggest that it may not serve as a reliable biomarker, despite overall decreased AchE with age [22]. Many other biological factors play a role in affecting overall AchE levels in both the brain and saliva, but significantly lower salivary AchE levels might prove to serve as a potential method of determining a compromised cholinergic system [2]. Salivary $A \beta 42$ seems to be a reliable biomarker, as all four studies in this review analyzing salivary $A \beta 42$ detected significant differences between $A D$ subjects and control subjects. One study reported no significant differences when analyzing other isoforms of $A \beta 42$, including $A \beta 40$ [3]. Two studies concluded significant differences in p-tau and t-tau levels between $A D$ subjects [17,12], but one of these studies reported significant variance in their data [12]. Statistical insignificance in salivary tau levels was determined in one study [18]. It was also reported that salivary tau expression was well characterized at the S396 phosphorylation site [12]. Carro et al.'s results show some validation of lactoferrin as a potential biomarker. Lactoferrin is present in several biological fluids and serves as part of the innate immune system. Some studies have suggested that certain pathogens may play a role in AD by compromising the function of the blood-brain barrier, thus enabling accelerated $A \beta 42$ growth. This may justify the reason for lower lactoferrin levels for individuals with $A D$, but further studies are needed to confirm this. The disaccharide trehalose was analyzed as well as a multitude of metabolites. There seems to be a correlation between the expression of trehalose and metabolism of the Amyloid Precursor Protein (APP) [25]. There were no significant differences in levels of trehalose, but there were significant differences in levels of various metabolites between AD subjects and controls. Further verification is necessary to confirm the validity of these findings.

Several analysis techniques were implemented throughout these studies, so a standardization by which to investigate salivary biomarkers would provide a more coherent method of selecting future $A D$ biomarkers. Many of these clinical studies featured a small sample size, so a large sample needs to be incorporated for future studies in order to establish reliable reference ranges for biomarker expression levels. Saliva production, circadian rhythms, and oral health are important factors which affect saliva composition. This necessitates further research into how these factors may affect the accuracy of saliva as a medium for $A D$ diagnosis. The precise mechanisms by which these biomarkers become secreted in saliva is not understood. There is still a need to acquire insightful knowledge of the mechanisms by 
which these biomarkers become secreted in saliva. Advancing the understanding of the pathophysiology of $A D$ requires a thorough comprehension of the association between saliva and $A D$.

\section{Conclusions}

This systematic review intends to determine the feasibility of various salivary biomarkers in order to achieve an early diagnosis of AD. Subject metrics, biomarker type, and methods of biomarker analysis were examined to establish a solid answer on the viability of a saliva test. The purported data indicates that certain salivary compounds may serve as valid AD biomarkers, but a large sample size and a standardization of biomarker analysis techniques must be implemented to further assess the reproducibility of the studies included in this systematic review.

\section{Declarations}

\section{Ethics Approval and Consent to Participate:}

Not applicable

Consent for Publication:

Not applicable

Availability of Data and Materials:

All analyzed and generated data in this study, as well as supplemental information are included in this manuscript.

Competing Interests: 
The author declares no potential conflicts of interest.

Funding:

Not applicable

Authors' Contributions:

MB conducted the literature search, extracted the data, selected the studies for inclusion, performed the statistical analysis, and wrote the manuscript.

Acknowledgements:

Not applicable

\section{References}

1. A. Martin Prince, World Alzheimer Report 2015: The Global Impact of Dementia: An Analysis of Prevalence, Incidence, Cost and Trends, Alzheimer's Disease International, 2015.

2. Bakhtiari, S., Moghadam, N. B., Ehsani, M., Mortazavi, H., Sabour, S., \& Bakhshi, M. (2017). Can Salivary Acetylcholinesterase be a Diagnostic Biomarker for Alzheimer?. Journal of clinical and diagnostic research : JCDR, 11(1), ZC58-ZC60. doi:10.7860/JCDR/2017/21715.9192

3. Bermejo-Pareja, F., Antequera, D., Vargas, T., Molina, J. A., \& Carro, E. (2010). Saliva levels of Abeta142 as potential biomarker of Alzheimer's disease: a pilot study. BMC neurology, 10, 108. doi:10.1186/1471-2377-10-108

4. “Biogen/Eisai Halt Phase 3 Aducanumab Trials | ALZFORUM," April 2019, https://www.alzforum.org/news/ research-news/biogeneisai-halt-phase-3-aducanumab-trials.

5. Blennow K. (2017). A Review of Fluid Biomarkers for Alzheimer's Disease: Moving from CSF to Blood. Neurology and therapy, 6(Suppl 1), 15-24. doi:10.1007/s40120-017-0073-9 
6. C.-B. Kim, Y. Y. Choi, W. K. Song, and K. B. Song, "Antibody based magnetic nanoparticle immunoassay for quantification of Alzheimer's disease pathogenic factor," Journal of Biomedical Optics, vol. 19, no. 5, article 051205, 2014.

7. Dementia. (n.d.). Retrieved from https://www.who.int/news-room/fact-sheets/detail/dementia.

8. E. Carro, F. Bartolomé, F. Bermejo-Pareja et al., "Early diagnosis of mild cognitive impairment and Alzheimer's disease based on salivary lactoferrin," Alzheimer's \& Dementia: Diagnosis, Assessment \& Disease Monitoring, vol. 8, pp. 131-138, 2017.

9. Farah, R., Haraty, H., Salame, Z., Fares, Y., Ojcius, D. M., \& Said Sadier, N. (2018). Salivary biomarkers for the diagnosis and monitoring of neurological diseases. Biomedical journal, 41(2), 63-87. doi:10.1016/j.bj.2018.03.004

10. H.-C. Lau, I. K. Lee, P. W. Ko et al., "Non-invasive screening for Alzheimer's disease by sensing salivary sugar using Drosophila cells expressing gustatory receptor ( $\mathrm{Gr} 5 \mathrm{a}$ ) immobilized on an extended gate ion-sensitive field-effect transistor (EGISFET) biosensor," PLoS One, vol. 10, no. 2, article e0117810, 2015.

11. Honig, L. S., Vellas, B., Woodward, M., Boada, M., Bullock, R., Borrie, M., Siemers, E. (2018). Trial of Solanezumab for Mild Dementia Due to Alzheimer's Disease. New England Journal of Medicine, 378(4), 321-330. doi: 10.1056/nejmoa1705971

12. H. Pekeles, H. Y. Qureshi, H. K. Paudel, H. M. Schipper, M. Gornistky, and H. Chertkow, “Development and validation of a salivary tau biomarker in Alzheimer's disease," Alzheimer's \& Dementia: Diagnosis, Assessment \& Disease Monitoring, vol. 11, pp. 53-60, 2018.

13. Loo, J. A., Yan, W., Ramachandran, P., \& Wong, D. T. (2010). Comparative human salivary and plasma proteomes. Journal of dental research, 89(10), 1016-1023. doi:10.1177/0022034510380414

14. Marksteiner, J., Oberacher, H., \& Humpel, C. (2019). Acyl-Alkyl-Phosphatidlycholines are Decreased in Saliva of Patients with Alzheimer's Disease as Identified by Targeted Metabolomics. Journal of Alzheimers Disease, 68(2), 583-589. doi: 10.3233/jad-181278

15. M. Lee, J. P. Guo, K. Kennedy, E. G. McGeer, and P. L. McGeer, "A method for diagnosing Alzheimer's disease based on salivary amyloid- $\beta$ protein 42 levels," Journal of Alzheimer's Disease, vol. 55, no. 3, pp. 1175-1182, 2017.

16. M. N. Sabbagh, J. Shi, M. Lee et al., "Salivary beta amyloid protein levels are detectable and differentiate patients with Alzheimer's disease dementia from normal controls: preliminary findings," BMC Neurology, vol. 18, no. 1, p. 155, 2018.

17. M. Shi, Y. T. Sui, E. R. Peskind et al., "Salivary tau species are potential biomarkers of Alzheimer's disease," Journal of Alzheimer's Disease, vol. 27, no. 2, pp. 299-305, 2011.

18. N. J. Ashton, M. Ide, M. Schöll et al., "No association of salivary total tau concentration with Alzheimer's disease," Neurobiology of Aging, vol. 70, pp. 125-127, 2018.

19. Prvulovic D, Hampel H. Amyloid beta (Abeta) and phospho-tau (ptau) as diagnostic biomarkers in Alzheimer's disease. Clin Chem Lab Med 49(3): 367-374 (2011). 
20. Q. Liang, H. Liu, T. Zhang, Y. Jiang, H. Xing, and A. H. Zhang, "Metabolomics-based screening of salivary biomarkers for early diagnosis of Alzheimer's disease," RSC Advances, vol. 5,no. 116, pp. 96074-96079, 2015.

21. Reale, M., Gonzales-Portillo, I., \& Borlongan, C. V. (2019). Saliva, an easily accessible fluid as diagnostic tool and potent stem cell source for Alzheimer's Disease: present and future applications. Brain Research, 146535. doi: 10.1016/j.brainres.2019.146535

22. Sayer, R., Law, E., Connelly, P. J., \& Breen, K. C. (2004). Association of a salivary acetylcholinesterase with Alzheimer's disease and response to cholinesterase inhibitors. Clinical Biochemistry, 37(2), 98104. doi: 10.1016/j.clinbiochem.2003.10.007

23. Serrano-Pozo, A., Frosch, M. P., Masliah, E., \& Hyman, B. T. (2011). Neuropathological alterations in Alzheimer disease. Cold Spring Harbor perspectives in medicine, 1(1), a006189. doi:10.1101/cshperspect.a006189

24. T. Huan, T. Tran, J. Zheng et al., "Metabolomics analyses of saliva detect novel biomarkers of Alzheimer's disease," Journal of Alzheimer's Disease, vol. 65, no. 4, pp. 1401-1416, 2018.

25. Tien, N. T., Karaca, I., Tamboli, I. Y., \& Walter, J. (2016). Trehalose Alters Subcellular Trafficking and the Metabolism of the Alzheimer-associated Amyloid Precursor Protein. The Journal of biological chemistry, 291(20), 10528-10540. doi:10.1074/jbc.M116.719286

26. Yilmaz, A., Geddes, T., Han, B., Bahado-Singh, R. O., Wilson, G. D., Imam, K., ... Graham, S. F. (2017). Diagnostic Biomarkers of Alzheimer's Disease as Identified in Saliva using 1H NMR-Based Metabolomics. Journal of Alzheimers Disease, 58(2), 355-359. doi: 10.3233/jad-161226

27. Zhang CZ, Cheng XQ, Li JY, Zhang P, Yi P, Xu X, et al. Saliva in the diagnosis of diseases. Int J Oral Sci 8(3): 133-37 (2016).

\section{Tables}

Table 1: Summary of results and subjects involved in analyzing salivary AD biomarker levels 


\begin{tabular}{|c|c|c|c|c|}
\hline & Study & & Result & Reference \\
\hline əsterase & $\begin{array}{l}0 \\
0 \\
0\end{array}$ & $\begin{array}{l}\text { Method of } \\
\text { quantification: } \\
\text { Ellman's } \\
\text { colorimetric } \\
\text { method } \\
\text { AD subjects: } 15 \\
\text { (9 male, } 6 \text { female) } \\
\text { Control subjects: } \\
15 \text { ( } 7 \text { male, } 8 \\
\text { female) } \\
\text { Mean age (AD): } \\
78.4 \\
\text { Mean age } \\
\text { (control): } 71\end{array}$ & $\begin{array}{l}\text { Higher AchE levels for } \mathrm{AD} \text {, but } \\
\text { statistically insignificant. }\end{array}$ & {$[2]$} \\
\hline əsterase & 0 & $\begin{array}{l}\text { Method of } \\
\text { quantification: } \\
\text { Ellman's } \\
\text { colorimetric } \\
\text { method } \\
\text { AD subjects } \\
\text { (AchE-1 therapy } \\
\text { responsive): } 22 \text { (7 } \\
\text { male, } 15 \text { female) } \\
\text { AD (AchE-1 } \\
\text { therapy } \\
\text { unresponsive):14 } \\
\text { (4 male, } 10 \\
\text { female) } \\
\text { Control subjects: } \\
11 \text { (6 male, } 5 \\
\text { female) } \\
\text { Mean age (AD } \\
\text { responsive): } 75 \\
\text { Mean age (AD } \\
\text { unresponsive):75 } \\
\text { Mean age } \\
\text { (control): } 71\end{array}$ & $\begin{array}{l}73 \% \text { lower AchE levels between } \mathrm{AD} \\
\text { and control }(\mathrm{p}<0.005), \text { negative } \\
\text { correlation between age and AchE } \\
\text { levels }(\mathrm{r}=-0.0 .73, \mathrm{p}<0.001)\end{array}$ & [22] \\
\hline & & Method of & $\mathrm{A} \beta 42 \mathrm{p}$-value mild $=0.043$ & [3] \\
\hline
\end{tabular}




\begin{tabular}{|c|c|c|}
\hline $\begin{array}{l}\text { quantification: } \\
\text { ELISA } \\
\text { AD subjects: } 70 \\
\text { ( } 21 \text { male, } 49 \\
\text { female) } \\
\text { PD subjects: } 51 \\
\text { (26 male, } 25 \\
\text { female) } \\
\text { Control subjects: } \\
56 \text { (17 male, } 39 \\
\text { female) } \\
\text { Mean age (AD): } \\
77.2 \\
\text { Mean age (PD): } \\
72.96 \\
\text { Mean age } \\
\text { (control): } 74.35\end{array}$ & $\begin{array}{l}\text { A } 442 \text { p-value (control/AD) }<0.05 \\
\text { Significantly higher } A \beta 42 \text { levels for } \\
\text { mild/moderate } A D \text { subjects vs control. } \\
\text { Significantly higher } A \beta 40 \text { levels for } P D \\
\text { and control. }\end{array}$ & \\
\hline $\begin{array}{l}\text { Method of } \\
\text { quantification: } \\
\text { ELISA } \\
\text { AD subjects: } 10 \\
\text { (3 male, } 7 \text { female) } \\
\text { Control subjects } \\
\text { and PD subject: } 27 \\
\text { (18 male,9 female) } \\
\text { Mean age (AD): } \\
70.1 \\
\text { Mean age } \\
\text { (control and } \mathrm{PD}) \text { : } \\
54.6\end{array}$ & $\begin{array}{l}\text { Higher } \mathrm{A} \beta 42 \text { for } \mathrm{AD} \text { vs. control } \\
(\mathrm{p}<0.001) \\
\text { Non-AD mean: } 22.06 \pm 0.41 \mathrm{pg} / \mathrm{mL} \\
\mathrm{AD} \text { mean: } 59.07 \pm 6.33 \mathrm{pg} / \mathrm{mL}\end{array}$ & [15] \\
\hline $\begin{array}{l}\text { Method of } \\
\text { quantification: } \\
\text { Nanobead } \\
\text { immunoassay } \\
\text { AD subjects: } 28 \\
\text { (age and gender } \\
\text { not provided) }\end{array}$ & $\begin{array}{l}\text { Significant differences for } \mathrm{A} \beta 42 \\
\text { levels } \\
\text { Insignificant levels for } \mathrm{A} \beta 40 \\
\text { No p-value provided during study }\end{array}$ & [6] \\
\hline
\end{tabular}




\begin{tabular}{|c|c|c|c|c|c|}
\hline & & $\begin{array}{l}\text { Control subjects: } \\
17 \text { (age and gender } \\
\text { not provided) }\end{array}$ & & & \\
\hline & 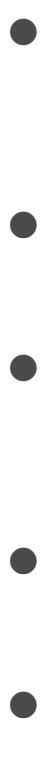 & $\begin{array}{l}\text { Method of } \\
\text { quantification: } \\
\text { ELISA } \\
\text { AD subjects: } 15 \\
\text { (7 male, } 8 \text { female) } \\
\text { Control subjects: } \\
7 \text { ( } 2 \text { male, } 5 \\
\text { female) } \\
\text { Mean age (AD): } \\
77.8 \pm 1.8 \\
\text { Mean age } \\
\text { (control): } 60.4 \pm 4.7\end{array}$ & & $\begin{array}{l}\text { Significant differences for } \mathrm{A} \beta 42 \text { vs. } \\
\text { control }(\mathrm{p}<0.001) \\
\text { Non-AD mean: } 21.1 \pm 0.3 \mathrm{pg} / \mathrm{mL} \\
\text { AD mean: } 51.7 \pm 1.6 \mathrm{pg} / \mathrm{mL}\end{array}$ & [16] \\
\hline & ○ & $\begin{array}{l}\text { Method of } \\
\text { quantification: } \\
\text { SIMOA } \\
\text { AD subjects: } 53 \\
\text { (23 male, } 30 \\
\text { female) } \\
\text { aMCI subjects: } \\
68 \text { (33 male, } 35 \\
\text { female) } \\
\text { Control subjects: } \\
160 \text { (66 male, } 94 \\
\text { female) } \\
\text { Mean age (AD): } \\
81.4 \pm 6.6 \\
\text { Mean age } \\
\text { (aMCI): } 79.8 \pm 7.4 \\
\text { Mean age } \\
\text { (control):78.0 } 66.7\end{array}$ & & $\begin{array}{l}\text { Statistically insignificant differences } \\
\text { for } \mathrm{AD} \text {, aMCI, and control }(\mathrm{p}=0.219)\end{array}$ & [18] \\
\hline s-tau, t- & & $\begin{array}{l}\text { Method of } \\
\text { quantification: } \\
\text { ELISA } \\
\text { AD subjects: } 21 \\
\text { (10 male, } 11\end{array}$ & & $\begin{array}{l}\text { Significance in the differences of } \mathrm{p} \text { - } \\
\text { tau/t-tau, } \mathrm{p} \text {-tau, and t-tau for AD vs. } \\
\text { control }(\mathrm{p}<0.05)\end{array}$ & [17] \\
\hline
\end{tabular}




\begin{tabular}{|c|c|c|}
\hline $\begin{array}{l}\text { female) } \\
\text { Control subjects: } \\
38(19 \text { male, } 19 \\
\text { female) } \\
\text { Mean age (AD): } \\
68.8 \\
\text { Mean age } \\
\text { (control): } 69\end{array}$ & & \\
\hline 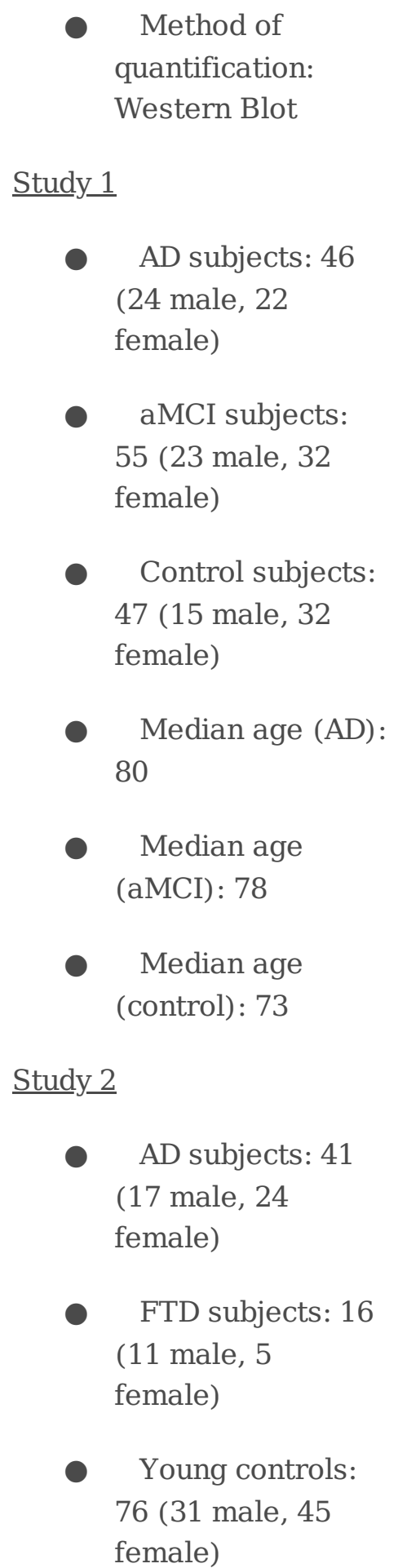 & $\begin{array}{l}\text { Significant } \mathrm{p} \text {-tau/t-tau ratio } \\
\text { difference for AD vs. elderly control } \\
\text { expressed at S396 ( } \mathrm{p}<0.05) \text {. } \\
\text { S396 sensitivity: } 73 \% \\
\text { S396 specificity: } 50 \% \\
\text { No correlation between salivary tau } \\
\text { levels and CSF tau. } \\
\text { No correlation between salivary tau } \\
\text { levels and hippocampal volume. }\end{array}$ & [12] \\
\hline
\end{tabular}




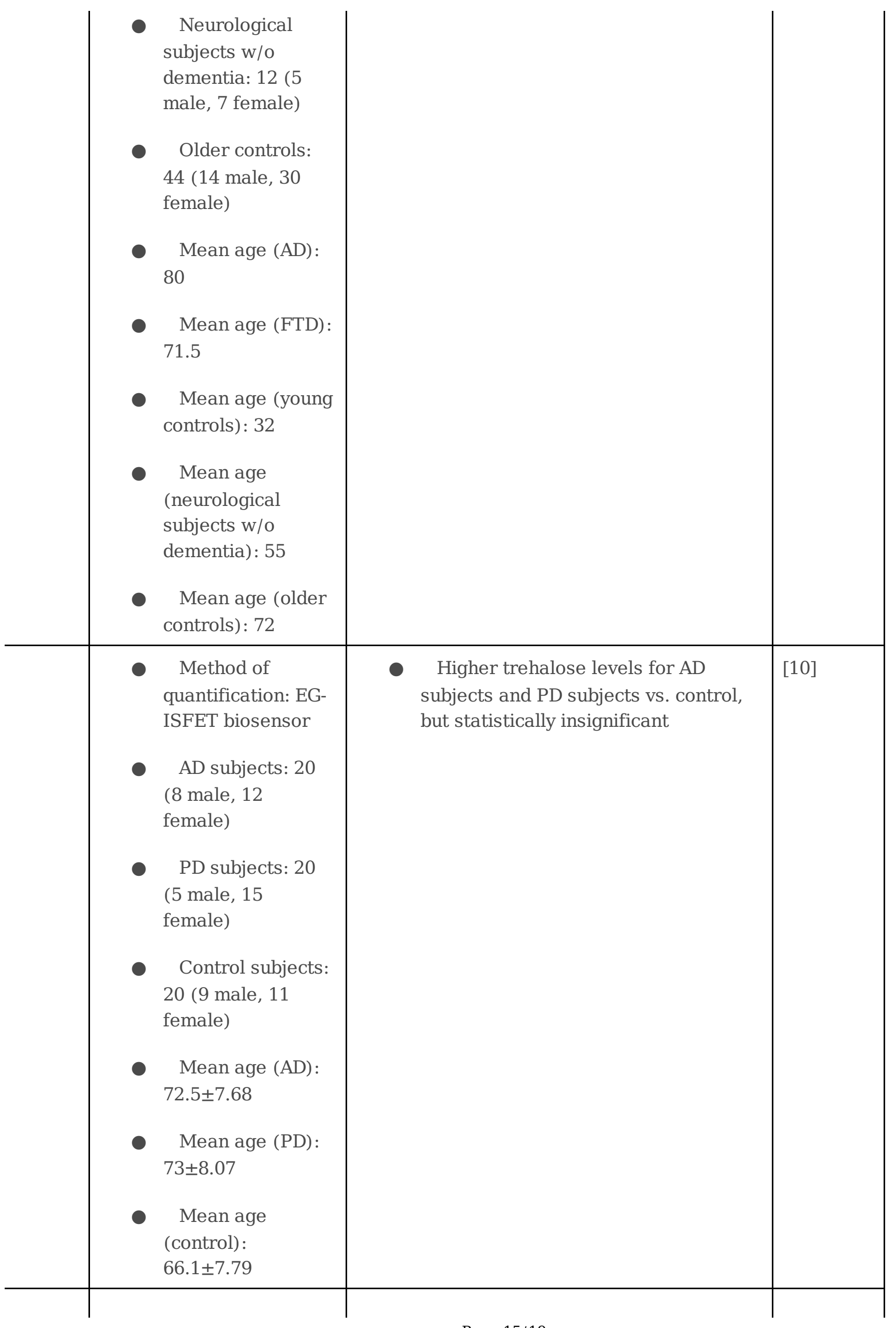

Page 15/19 


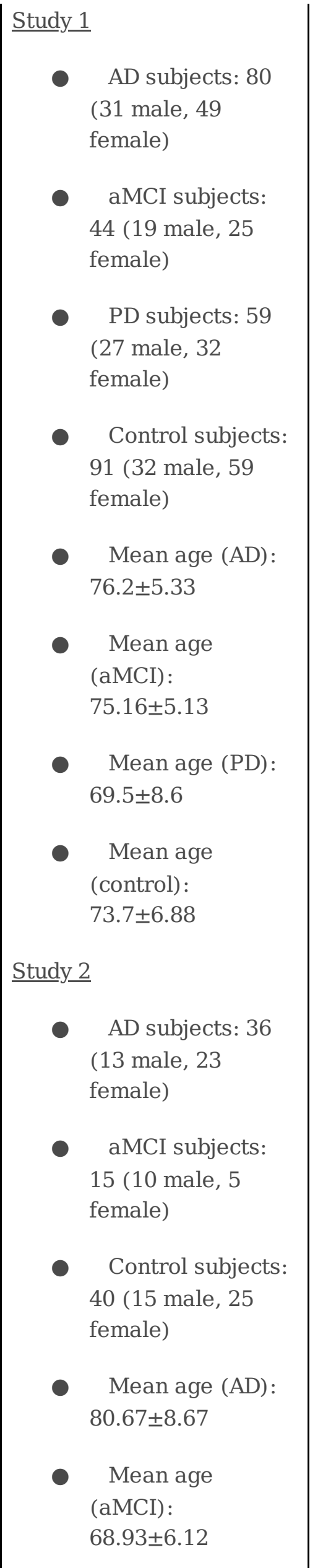

- Significantly lower levels of lactoferrin for $\mathrm{AD}$ and $\mathrm{aMCI}$ vs. control $(p<0.001)$

- PD subjects had significantly higher lactoferrin levels vs. controls

- Cutoff value between $\mathrm{AD} / \mathrm{aMCI}$ and controls: $7.43 \mu \mathrm{g} / \mathrm{mL}$ 


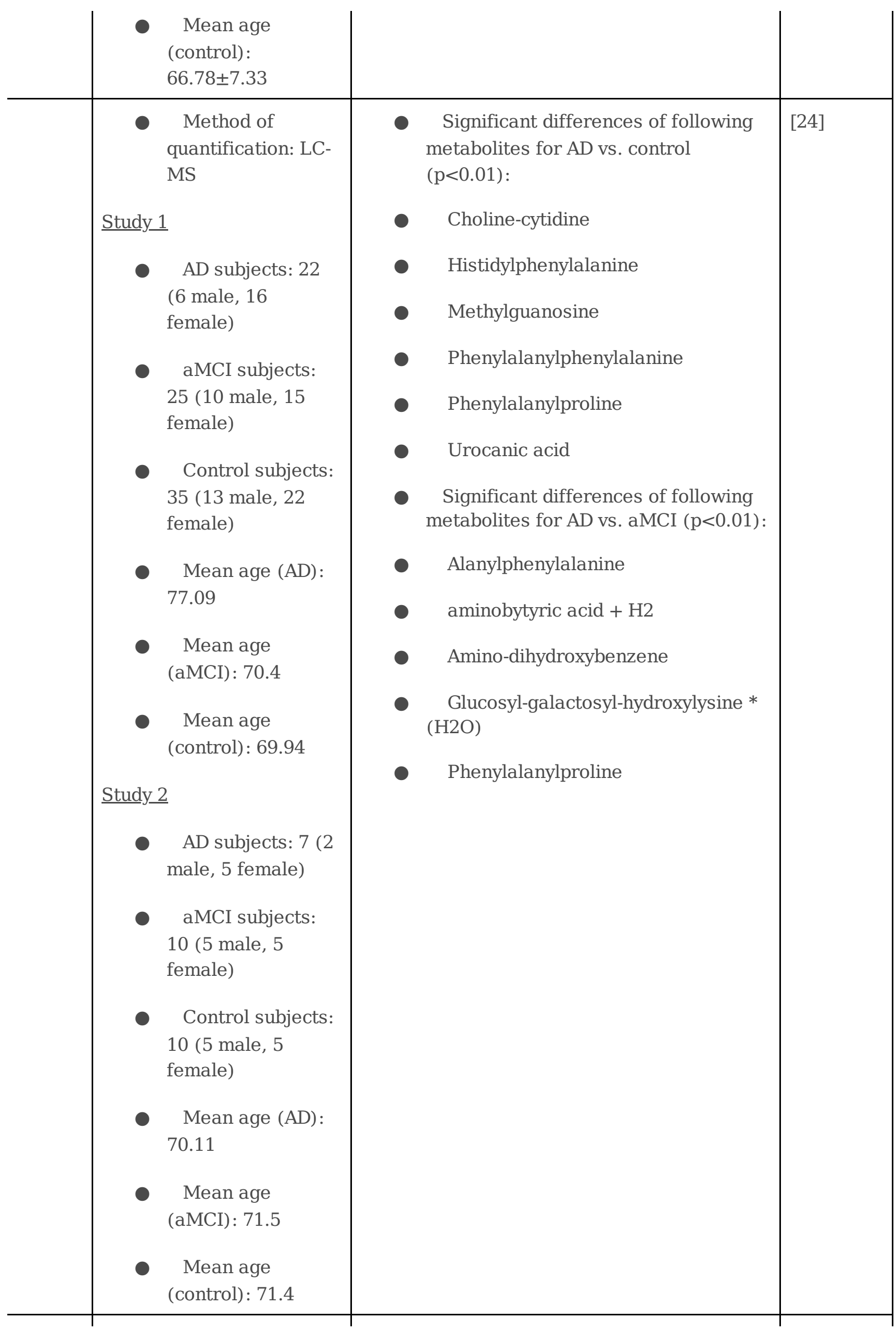


- Method of quantification: UPLC-MS

- $\quad \mathrm{AD}$ subjects: 256 (124 male, 132 female)

- Control subjects: 218 (102 male, 116 female)

- Mean age (AD): $78.6 \pm 6.80$

- Mean age (control): $77.9 \pm 5.60$
- Significantly higher levels of spinganine-1-phosphate and ornithine for $\mathrm{AD}$ vs. control $(\mathrm{p}<0.01)$

- Significantly lower levels of inosine for $A D$ vs. control $(p<0.01)$

\section{Figures}




\section{Initial Publications Screened (through Google Scholar and PubMed): 77}

\section{Publications Excluded: 64}

\section{Publications Selected for Review: 13}

Figure 1

Publication Search and Selection Flowchart.

\section{Supplementary Files}

This is a list of supplementary files associated with this preprint. Click to download.

- SystematicReviewPRISMAChecklist.doc 